\title{
Mutual Influences of Urban Microclimate and Urban Trees: An Investigation of Phenology and Cooling Capacity
}

\author{
Celina H. Stanley ${ }^{1,2, *}$, Carola Helletsgruber ${ }^{2}$ and Angela Hof ${ }^{2}(\mathbb{D}$ \\ 1 Department of Landscape Change and Management, Leibniz Institute of Ecological Urban and Regional \\ Development, 01217 Dresden, Germany \\ 2 Department of Geography and Geology, University of Salzburg, 5020 Salzburg, Austria \\ * Correspondence: C.Stanley@ioer.de; Tel.: +49-351-467-9269
}

Received: 31 May 2019; Accepted: 21 June 2019; Published: 26 June 2019

check for updates

\begin{abstract}
This paper presents an empirical study on urban tree growth and regulating ecosystem services along an urban heat island (UHI) intensity gradient. The UHI effect on the length of the growing season and the association of cooling and shading with species, age, and size of trees was studied in Salzburg, Austria. Results show that areas with a low UHI intensity differed from areas with a medium or high UHI intensity significantly in three points: their bud break began later, the leaf discoloration took longer, and the growing season was shorter. After leaves have developed, trees cool the surface throughout the whole growing season by casting shadows. On average, the surfaces in the crown shade were $12.2^{\circ} \mathrm{C}$ cooler than those in the sun. The tree characteristics had different effects on the cooling performance. In addition to tree height and trunk circumference, age was especially closely related to surface cooling. If a tree's cooling capacity is to be estimated, tree age is the most suitable measure, also with respect to its assessment effort. Practitioners are advised to consider the different UHI intensities when maintaining or enhancing public greenery. The cooling capacity of tall, old trees is needed especially in areas with a high UHI intensity. In the future, species differences should be examined to determine the best adapted species for the different UHI intensities. The present results can be the basis for modeling future mutual influences of microclimate and urban trees.
\end{abstract}

Keywords: growing season; bud break; surface temperature; urban heat island; urban microclimate; urban trees

\section{Introduction}

Cities are the most important living space of humans, at least as measured by the proportion of the population living in them. By 2030, global urban population is projected to increase to $70 \%$. This growing urbanization is causing huge changes in the urban environment [1]. One result of these transformations is the urban heat island (UHI) effect, which is characterized by higher air and surface temperatures compared to the rural environment. Factors contributing to this effect include, for example, the coverage of natural surfaces with material that absorbs the solar radiation more strongly and the industrial heat output. The increase in temperature has enormous negative consequences for the urban population and lowers their quality of life as air and water quality decrease, as well as the thermal comfort. A particular risk comes from the increasing and prolonged heatwaves that lead to a higher number of fatalities [2]. The projected increase in the average annual temperatures suggests an intensification in the UHI effect [3].

However, urban green spaces can mitigate the UHI effect. In contrast to sealed surfaces which have high runoff and low evaporation rates, plants remove energy from their ambient air in the form 
of heat and thus evaporate the water they store. Through evapotranspiration, the plants not only cool themselves but also the air temperature in the immediate vicinity [4]. Furthermore, urban trees provide indirect temperature cooling by shading the surface. The crown blocks the solar radiation and the surface heats up less. Therefore, due to less radiation, the air temperature under the crown heats up much less as well [5].

The extent of the cooling effects depends on various environmental factors and plant characteristics [4]. Many studies deal with the positive benefits of large green spaces, such as city parks, whereas urban trees are rarely in focus. Yet even individual trees show a cooling effect [6]. One study identified correlations between air temperature cooling and leaf color, foliage density, leaf thickness, and structure of the leaves [7]. Another study about surface cooling showed that with an increasing leaf area index (LAI), the asphalt temperature decreases, with this effect being independent of tree species; however, there was no corresponding effect on a grassy surface [8]. Mao et al. studied two streets, one lined with deciduous trees and the other lined with coniferous trees [9]; due to a higher evapotranspiration capacity of the deciduous trees, the temperatures on this street were lower. Differences in cooling performance occur even between different tree species. These differences are related to the trees' characteristics, such as height or crown shape [6]. Gillner and colleagues [10] compared six species of trees for their capacity to increase relative humidity and to reduce surface and air temperatures. There were significant differences in the microclimatic impact of the species. Corylus colurna L. and Tilia cordata Mill. provided particularly high cooling, whereas Ulmus $\times$ hollandica 'Lobel' had the lowest cooling values. The authors used leaf area density (LAD) as a tree characteristic with which they associated surface cooling. Across all tree species, there were strong positive correlations between surface cooling and LAD [10].

Though trees can mitigate UHI, not all species are adapted to it. Urban and street trees only reach on average about $25 \%-50 \%$ of their potential age range [11]. This is partly due to the wrong choice of tree species [11] and illustrates the need to follow up with the effects of the site conditions on the trees.

Temperature is one of the most important factors affecting the phenological development of trees. Besides bud break, flowering or leaf fall is also determined by temperature. Temperature-induced changes in phenological development were detected in different tree species and in different study areas. A study carried out in England with more than 200 species showed, for example, that tree blossom began four days earlier when the average annual temperature rose by one degree Celsius [12]. In addition to the average annual temperature, researchers of the Landesanstalt für Umwelt, Messungen und Naturschutz Baden-Württemberg (LUBW) found another temperature-related climate parameter with the cumulative sum of the average daytime temperatures, which has a connection with the occurrence of phenological phases [13]. Furthermore, an analysis of the International Phenological Gardens of Europe showed a clear gradient in bud break between the warm countries of southern Europe and the cold north [12]. Additionally, Chmielewski and Rötzer [12] found that spring temperatures decisively determine the timing of leaf emergence. The higher the air temperatures were between February and April, the earlier the buds break. This was also the case in so-called "extreme years" when the emergence started particularly early or late according to the temperature. They found that a temperature rise of one degree Celsius was associated with a growing season which began 6.7 days earlier in Europe [12]. Thus, it becomes obvious that warming due to climate change and the higher temperatures in the city generated by the UHI compared to the surrounding area must have an impact on the timing of bud break. Zipper and colleagues [14] studied the relationship between bud break and the location of the tree. There was a significantly longer (8.0-10.5 days) growing season in urban areas compared to rural areas. The length of the growing season in parks was only about 5 days longer than in rural areas. This can be explained by the park cool island effect. Despite the inner-city location of the parks, the UHI effect is less pronounced than in the built-up city due to the temperature reduction of the vegetation [14].

Assuming that the temperature, as key driver, determines the start of bud break, duration of leaf unfolding and the growing season, and that differences between impervious cover and urban green 
space are found, the question arises as to what extent UHI intensity is different within the built-up city and has an influence on the bud break and growing season of urban trees. In the present study, mutual effects between UHI and urban trees were investigated. On the one hand, it was determined how different UHI intensities affect the phenological phases (bud break and leaf discoloration) as well as the length of the entire growing season of urban trees. On the other hand, we analyzed to what extent urban trees reduce the surface temperature and to which tree characteristics this cooling performance is related. By combining these two aspects, recommendations for applied urban planning are made.

\section{Materials and Methods}

\subsection{Study Sites and Objects}

The study was conducted in the City of Salzburg, Austria (coordinates: $47^{\circ} 47^{\prime} \mathrm{N}, 13^{\circ} 00^{\prime} \mathrm{E}$; altitude: $436 \mathrm{~m}$ ). According to the Köppen climate classification, the climate in Salzburg is a marine west coast $(\mathrm{Cfb})$ climate. The daily mean temperature varies between $-0.8{ }^{\circ} \mathrm{C}$ in January and $18.6{ }^{\circ} \mathrm{C}$ in July. Due to the location at the northern rim of the Alps, the amount of precipitation is rather high with an amount of $1336 \mathrm{~mm} /$ year, mainly in the summer months [15].

In order to investigate the influence of the varying UHI intensities on bud break, first the warmer and cooler areas of the city had to be identified. For this, the number of summer days was used as a climatic parameter. Summer days are defined as all those days with a daily maximum temperature of at least $25^{\circ} \mathrm{C}$ [16]. The information was obtained from a layer of the Zentralanstalt für Meteorologie und Geodynamik (ZAMG) SISSI project. The layer maps the average number of summer days per year for the period from 1971 to 2000 with a spatial resolution of $100 \times 100 \mathrm{~m}$. The maps were obtained from a microscale urban climate model which, among other things, takes building structure into account [17]. First, the layer had to be reduced to the urban areas with an impervious cover greater than $30 \%$. Otherwise, the green areas, especially due to the city mountains in Salzburg, would have distorted the classification. Subsequently, a UHI intensity gradient was generated. With the help of "natural breaks" classification, the urban area was classified into three UHI-intensity categories. As the name suggests, this classification searches the values for natural breaks and ensures that the categories themselves are as homogeneous as possible while contrasting each other [18]. The least number of summer days occurs in category 1 areas, with up to 55.8 summer days per year. Accordingly, these areas have a low UHI intensity. In category 2 areas, there are 55.9-64.8 summer days per year, which is why these areas have a medium UHI intensity. In category 3 areas, there are more than 64.8 summer days per year. Accordingly, these areas have a high UHI intensity. The locations of the observed tree species were selected within these three categories, and the study sites are listed in Table 1 . The selection of tree species included several considerations. In addition to the number of individuals, the Citree database played a major role. This database is a supporting tool for choosing the optimal trees for urban areas by providing information about more than 390 tree and shrub species, including site characteristics, for example [19]. By analyzing the tree register of Salzburg (a map showing all public trees), the most common species of the publicly owned and managed tree stock were selected. The higher the number of individuals, the higher the effect of the species on the urban climate. To ensure that the selected tree species were adapted to the future urban climate, the species drought tolerance, hardiness, heat tolerance, and late frost tolerance were analyzed by using the Citree database. Using the tree register, eight study sites were identified. 
Table 1. Overview of the study sites with urban heat island (UHI) intensity/category, tree species, and number of trees.

\begin{tabular}{cccc}
\hline Study Sites & UHI Intensity/Category & Tree Species & Number of Trees \\
\hline Berchtesgadner Straße & low/1 & Acer platanoides & 4 \\
Max-Reinhardt-Platz & low/1 & Tilia cordata & 8 \\
Hofhaymer Allee & medium/2 & Tilia cordata & 6 \\
Otto-Holzbauer-Straße & medium/2 & Acer platanoides & 8 \\
Erzabt-Klotz-Straße & high/3 & Tilia cordata & 3 \\
Franz-Josef-Straße & high/3 & Aesculus $\times$ carnea & 6 \\
Guggenmoosstraße & high/3 & Corylus colurna & 6 \\
Südtiroler Platz & high/3 & Acer platanoides & 5 \\
\hline
\end{tabular}

\subsection{Phenological Monitoring}

For the phenological monitoring in spring, we used the well-established method presented by Wesolowski and Rowinski [20]. They developed a scale of point values from 0 to 2 for assessing the development status of a leaf bud. For each observation day, ten randomly selected apical buds in the upper, south-exposed part of the crown are evaluated and their sum is calculated [20]. The monitoring starts when all buds are closed and thus evaluated as having zero points. As soon as all ten leaves are completely developed and each scores two points, the monitoring is finished. To record the evaluation of the buds, an observation sheet was specially designed. The phenological monitoring according to Wesolowski and Rowinski's instructions was carried out every three days from 21 March 2018 to 5 May 2018.

To test this, further phenological monitoring was conducted during the autumn of 2018. Following and adapting the methodology described in the teaching and learning materials of the European Union (EU)'s COMENIUS Project named BEAGLE (Biodiversity Education and Awareness to Grow a Living Environment) [21], four scores were used:

(0) No leaf discoloration and/or leaf fall

(1) Beginning leaf discoloration and/or leaf fall ( $<50 \%$ of leaves)

(2) Pronounced leaf discoloration and/or leaf fall ( $\geq 50 \%$ of leaves)

(3) Complete leaf discoloration and/or leaf fall

The phenological monitoring in the autumn was done once in a week starting on September 13, 2018 and ending on November 27, 2018. By using the beginning and end of leaf discoloration, we calculated the length of leaf discoloration.

\subsection{Tree Physiognomy}

For all observation trees, the height, trunk circumference at breast height, and leaf area index (LAI) were measured. Using these data, the tree age, crown area, and crown volume were further calculated. The tree height was measured using a Leica DISTOTM D810 Touch (Leica Geosystems, Heerbrugg, Switzerland). To determine the LAI, an LAI-2200C Plant Canopy Analyzer from LI-COR (Lincoln, NE, USA) was used. Four LAI measurements at breast height were made per tree along the four cardinal directions using a $90^{\circ}$ cap. By averaging the four values, differences in the crown density were balanced. The measured values were then edited in the FV2200 software from LI-COR (2.1.1, Lincoln, NE, USA). Among other things, the crown shape was specified, which was previously extracted from photos following the methodology presented in the device manual. After adaptation of the crown shape, the LAI was interpreted as foliage density for single tree measurements [22]. Thus, crown area and crown volume were calculated. Tree age was estimated using the trunk circumference. Based on earlier surveys of growth rates, tables exist for the species-specific annual growth in centimeters. If the current trunk circumference is divided by this factor, then the approximate age of the tree is obtained [23]. 


\subsection{Microclimatic Measurements}

The climatic parameter used was surface cooling. The microclimate was measured using the difference of the surface temperatures between the crown-shaded area and the full sun-exposed area (compare [10]). The measurements were carried out using an Infrared Radiometer, Model MI-220, from Apogee Instruments Inc. (Logan, UT, USA). The device was fixed on a tripod to make sure that all measurements were carried out from the same height $(0.55 \mathrm{~m})$ and angle $\left(45^{\circ}\right)$. To calculate the cooling effect, the surface temperature in the shade of each tree crown was measured and once per study site on a full sun-exposed reference area. For all temperature measurements, the same height and angle were used. The reference areas were as close as possible to the studied trees and had the same surface type. Because of the changing sun position, it was important to measure the surface temperature of the tree crown-shaded area as centrally as possible.

To minimize the variations of surface temperatures linked to the changing atmospheric conditions during a day and between different days, all measurements were run through on one day (July 24, 2018) between 13:30 and 15:30 under cloudless conditions.

\subsection{Statistical Analysis}

One-way ANOVAs were performed to assess whether the beginning of bud break and length of leaf unfolding, the onset and length of leaf discoloration, and the length of growing season differed between the three UHI intensities. In the case of significant results, Tukey post-hoc tests were conducted to test all pairwise comparisons. The correlations between surface cooling and tree characteristics (tree height, trunk circumference, age, LAI, crown area, and crown volume) were assessed using Pearson's r. For all statistical data processes, we used R version 3.4.4 (R Core Team, Vienna, Austria). The level of significance was set at $p<0.05$.

\section{Results}

\subsection{Effect of UHI Intensity on Tree Physiognomy}

In order to assess the extent to which three different UHI intensities influence the length of the growing season and, ultimately, tree physiognomy, the results of the phenological monitoring in spring and autumn were compared with respect to the three defined categories.

Using data from the phenological monitoring in spring, a significant difference was observed between the three UHI intensities with respect to the beginning of the bud break, $F(2,51)=15.4$, $p<0.001$. On average, the leaves of the trees began to develop earlier in areas with a high UHI intensity compared to areas with a low UHI intensity (Figure 1A). Significant differences were found between categories 1 and $2(p=0.001)$ and between categories 1 and $3(p<0.001)$ using Tukey post-hoc tests. On average, the bud break of the trees in categories 2 and 3 began on April 7 (SD $=2$ days) and on April 5 (SD $=5$ days), respectively. However, this difference was not significant $(p=0.363)$. In contrast, the leaves in category 1 began to develop on average on 13 April (SD $=4$ days). 

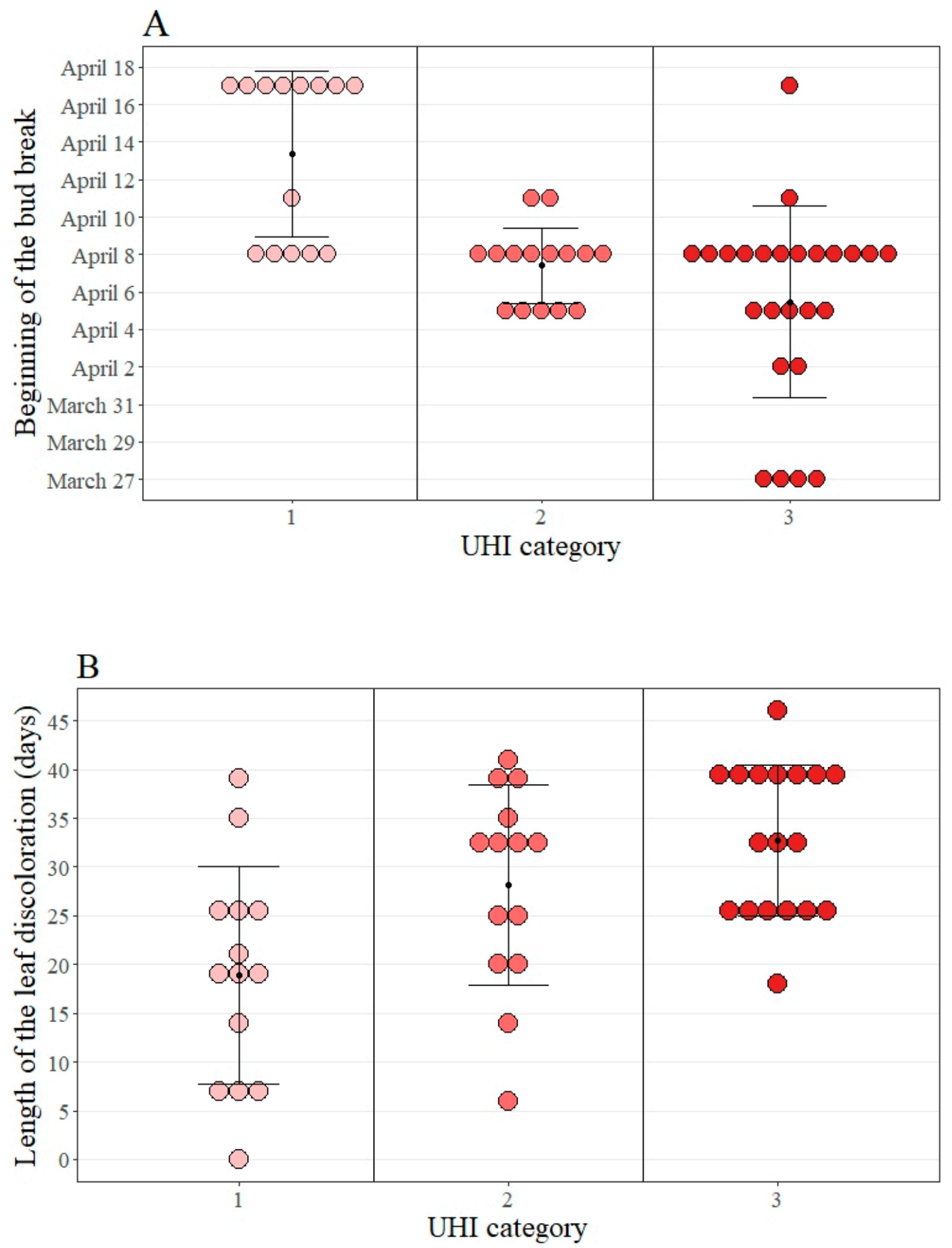

Figure 1. Cont. 


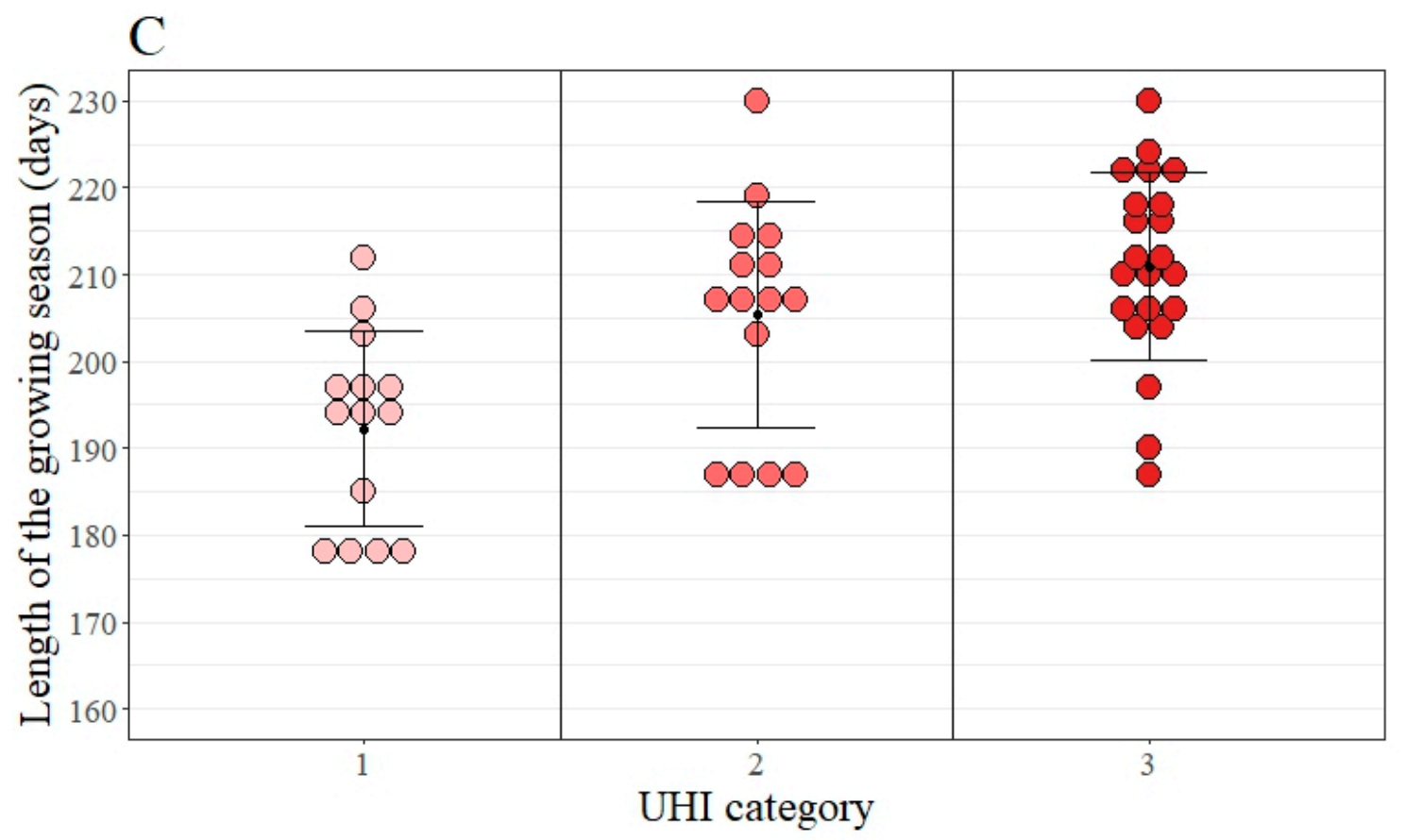

Figure 1. (A) The beginning of the bud break, (B) the length of the leaf discoloration, and (C) the length of the growing season of the investigated trees, separated by UHI intensity. The figure additionally shows the means and standard deviations.

The average length of the leaf unfolding varied between 11 days ( $\mathrm{SD}=3$ days) in areas with a low $\mathrm{UHI}$ intensity and 13 days in areas with a medium $(\mathrm{SD}=3)$ or high ( $\mathrm{SD}=7$ days) $\mathrm{UHI}$ intensity. However, this difference was not significant, $F(2,51)=1.0, p=0.379$.

The phenological monitoring in autumn provided information on the relationship between the onset and the length of leaf discoloration with UHI intensity. The first tree started to discolor on September 13 and the last on October 18. On average, the trees in areas with a medium UHI intensity started to discolor earliest, namely, on September 30 ( $S D=7$ days). In comparison, the trees in the warmest urban areas began to discolor on average on October 3 (SD $=6$ days) and the trees in the coolest areas only on October 5 ( $\mathrm{SD}=8$ days). However, the differences between the three categories were not significant, $F(2,45)=2.1, p=0.134$.

In contrast, there was a significant difference between the three UHI intensities with respect to the length of leaf discoloration, $F(2,45)=8.8, p<0.001$. On average, complete discoloration took 19 days $(\mathrm{SD}=11$ days $)$ in areas with a low $\mathrm{UHI}$ intensity, 29 days $(\mathrm{SD}=11$ days) in areas with a medium UHI intensity, and 34 days (SD = 8 days) in areas with a high UHI intensity (Figure 1B). Using Tukey post-hoc tests, we found that category 1 was significantly different from both category $2(p=0.019)$ and category $3(p<0.001)$, but there was no significant difference between categories 2 and $3(p=0.466)$.

Finally, the two monitoring periods (spring and autumn) were combined to determine the length of the growing season (Figure 1C). The period between the beginning of bud break and the completion of leaf discoloration differed significantly among the three UHI intensities, $F(2,50)=12.7, p<0.001$. Using Tukey post-hoc tests, significant differences were found between categories 1 and $2(p=0.014)$ and between categories 1 and $3(p<0.001)$ but not between categories 2 and $3(p=0.166)$. The average length of the growing season was 192 days ( $S D=11$ days) in category 1, 205 days (SD = 13 days) in category 2, and 213 days (SD $=12$ days) in category 3 .

\subsection{Estimation of Surface Cooling Using Tree Characteristics}

The average surface cooling of the examined trees was $12.2^{\circ} \mathrm{C}\left(\mathrm{SD}=3.8^{\circ} \mathrm{C}\right)$. The values ranged from at least $6.4{ }^{\circ} \mathrm{C}$ up to a maximum cooling of $22.4^{\circ} \mathrm{C}$. 
For a more detailed investigation of surface cooling, all trees were aggregated regardless of tree species or UHI intensity. Table 2 gives an overview of the investigated tree characteristics that were associated with surface cooling.

Table 2. Overview of tree characteristics with mean values, standard deviations, minima, and maxima.

\begin{tabular}{cccc}
\hline Tree Characteristic & Mean (SD) & Min & Max \\
\hline Tree height $(\mathrm{m})$ & $10.9(2.2)$ & 7.0 & 16.0 \\
Trunk circumference $(\mathrm{cm})$ & $91.2(30.3)$ & 43.0 & 142.0 \\
Age $($ years $)$ & $33.4(11.1)$ & 17.0 & 56.0 \\
LAI $\left(\mathrm{m}^{2} / \mathrm{m}^{2}\right)$ & $1.5(0.7)$ & 0.5 & 3.1 \\
Crown area $\left(\mathrm{m}^{2}\right)$ & $32.6(13.2)$ & 8.9 & 63.0 \\
Crown volume $\left(\mathrm{m}^{3}\right)$ & $129(79.4)$ & 19.1 & 338.0 \\
\hline
\end{tabular}

From these six criteria, the one that best predicts surface cooling can be identified. For this purpose, the correlations were determined between surface cooling and tree height, trunk circumference, age, LAI, crown area, and crown volume (Table 3). Surface cooling turned out to be most strongly related to age, followed by trunk circumference and tree height. The tree characteristics themselves were also strongly interrelated. All the correlations listed in Table 3 were significant $(p<0.05)$.

Table 3. Overview of correlations among the tree characteristics and surface cooling.

\begin{tabular}{cccccccc}
\hline Tree characteristics & $\mathbf{1}$ & $\mathbf{2}$ & $\mathbf{3}$ & $\mathbf{4}$ & $\mathbf{5}$ & $\mathbf{6}$ & $\mathbf{7}$ \\
\hline 1 Surface cooling & - & & & & & & \\
2 Tree height & $0.51^{* *}$ & - & & & & & \\
3 Trunk & $0.55^{* * *}$ & $0.85^{* * *}$ & - & & & & \\
circumference & & & & & & \\
4 Age & $0.61^{* * *}$ & $0.77^{* * *}$ & $0.93^{* * *}$ & - & & \\
5 LAI & $-0.34^{*}$ & $-0.45^{* *}$ & $-0.49^{* *}$ & $-0.41^{*}$ & - & \\
6 Crown area & $0.47^{* *}$ & $0.72^{* * *}$ & $0.81^{* * *}$ & $0.72^{* * *}$ & $-0.49^{* *}$ & - \\
7 Crown volume & $0.45^{* *}$ & $0.77^{* * *}$ & $0.83^{* * *}$ & $0.72^{* * *}$ & $-0.46^{* *}$ & $0.95^{* * *}$ & -
\end{tabular}

* The correlation is significant at the $p<0.05$ level, ${ }^{* *}$ The correlation is significant at the $p<0.01$ level, ${ }^{* * *}$ The correlation is significant at the $p<0.001$ level.

\section{Discussion}

In this study, the mutual influence of urban trees and UHI intensity was examined. On the one hand, the effects of UHI intensity on tree phenology were investigated. On the other hand, the effectiveness of trees in cooling the surface was considered with regard to their characteristics. Significant effects were found for both research questions which are discussed separately below.

\subsection{Effect of UHI Intensity on Tree Phenology}

The phenological monitoring in spring and autumn showed significant differences between the UHI intensities with respect to the beginning of the bud break, the length of the leaf discoloration, and the length of the growing season. The trees in cooler areas began later with their bud break, their leaves were completely discolored after a shorter time in the autumn, and their entire growing season was significantly shorter. It can thus be deduced that as temperatures increase, the bud break is accelerated and the growing season is prolonged. These findings are consistent with those of other studies. It was frequently stated that the elevated temperatures are a major reason for the increasingly early beginning of the bud break $[12,20,24]$. An increase in temperature of one degree Celsius causes phenological processes around the world to begin four to six days earlier, which is why the results of phenological observations are also useful indicators of the progress of climate change [24]. Above all, earlier or greater warming in the spring promotes an earlier beginning of the bud break [25]. Some of the studies on the influence of temperature on the phenology of trees are not confined to urban areas 
but also include forests [12]. As little was known about the trees' response specifically to the elevated temperatures in the city compared to the surrounding area, Zipper and colleagues [14] investigated this issue with a longitudinal study over three years. They were able to prove that UHI is reflected in the phenology of the trees. Compared to the surrounding area, the growing season of trees in the city was on average five days longer. Measurements in urban parks showed a weakened effect regarding the extended length of the growing season, which was explained by the park cool island effect [14]. The results of the present study substantiate the relationship between temperature rise and premature beginning of bud break as well as extended length of the growing season from another point of view. It is not the general temperature increase that is investigated, but rather inner-urban temperature variations. Even within the urban area, UHI intensity or temperature differences occur. These temperature differences have an impact on tree phenology regardless of what causes them, whether it be the degree of impervious cover, the density of buildings, or wind blocks. However, our data show no continuous progression between the three UHI intensities regarding the three parameters, namely, beginning of the bud break, length of the leaf discoloration, and length of the growing season. Instead, there were significant differences between trees in areas of categories 1 and 2 as well as categories 1 and 3. Therefore, it is reasonable to assume that there is a threshold value in the temperature at which, for example, the beginning of the bud break is forced. Regarding the UHI intensities, the biggest phenological differences occur between categories 1 and 2 . If the UHI intensity increases even further, from that point on, for example, no significantly earlier beginning of the bud break is expected. The realization that the city is a small-scale mosaic of UHI intensities and that this has an impact on the phenology of the trees turns out to be extremely relevant for urban planning practices. Our findings show that it is worth taking into account the local UHI intensity when choosing tree species to maximize the benefits, as urban trees may grow larger and provide more ecosystem services if the urban forest is strategically planted [26]. In cooler areas, species with a long growing season should therefore be planted to benefit from the regulating ecosystem services of the trees as early as possible and well into the autumn. There are already studies on these species-specific reactions to temperature and their phenological characteristics which will be crucially important in the future $[24,27]$. This makes it possible to find species which can adapt to rising temperatures and at the same time make the city more resilient against them [28]. In addition, more research attention should be paid to the second research question in the present study, that is, how significant is the cooling effect of the trees and which tree characteristics are associated with it.

\subsection{Estimation of Surface Cooling Using Tree Characteristics}

All investigated tree characteristics correlated moderately to strongly with surface cooling. Only the LAI correlated negatively with both surface cooling and the other tree characteristics. The negative correlation between the LAI and surface cooling contradicts the results of other studies $[8,10]$. A full discussion of these findings is beyond the scope of the present paper. Instead, the focus is on the other tree characteristics that were positively related to surface cooling. Nevertheless, it is worth noting that, through its frequent use, the LAI is established as a proven tool for predicting the climate impact of trees [8]. Despite all of this, the LAI also has weaknesses. A comparison of different studies that determined the LAI in a direct and indirect way showed an underestimation of the LAI when using measuring instruments for indirect estimation. This underestimation varied between $25 \%$ to $50 \%$ [29]. In addition, the effort needed to collect the LAI can be determined from the method description, which is another reason to find an alternative measure. Therefore, a comparison of the correlations of different tree characteristics with surface cooling should indicate which other parameters, and ones that are possibly easier to assess, are closely related to the cooling performance of a particular tree.

Two possible parameters, tree height and crown volume, have already shown positive correlations with climatic cooling. With increasing tree size and crown, the trees blocked more radiation [30]. Likewise, the density of the crown affected the amount of blocked radiation and surface cooling [10]. This ultimately resulted in a difference between the studied tree species in their potential to cool 
the surface. However, Gillner and colleagues also pointed out that the species had different mean heights and were therefore somewhat limited in their cooling capacity [10]. Therefore, in the present study, the data measured and collected for the investigated species were combined in order to make statements solely about the tree characteristics.

Age showed the greatest correlation with surface cooling. In addition, the age was strongly related to the trunk circumference. This is due to the calculation method of a tree's age, which is a combination of a species-specific factor and the trunk circumference [23]. That is why the calculated tree age is only an approximation of the real tree age and is, among other things, influenced by geographic location. With regard to the assessment methods of the individual tree characteristics and the correlations of these with surface cooling, the tree age seems particularly suitable for predicting the surface cooling capacity of a tree. Since age, unless known, is calculated from the trunk circumference, it is unaffected by trimming, in contrast to the other tree characteristics. Compared to the mere circumference of the trunk, age has the advantage of taking into account species-specific growth rates, with only a minor additional effort.

Nevertheless, this does not mean that age is responsible for the cooling capacity of a tree. There exist other external factors like water availability that influence the cooling capacity. Due to a lack of water, the evaporation capacity of the trees is reduced and thus also their cooling capacity [10].

\section{Conclusions}

The present study has shown that, on the one hand, UHI is not uniform throughout the urban area and that the different intensities affect the phenological development of trees. When planting trees with the intention of positively influencing the urban climate, it is recommended that planners consider the city as a small-scale UHI mosaic. On the other hand, differences in tree characteristics affect the cooling of the UHI. Based on the interrelation of UHI and city trees, practical recommendations for action are given. In areas with a more pronounced UHI, it is even more important to plant species that grow tall and form a large crown to mitigate UHI in the best possible way. Small ornamental trees are not an adequate substitute from a climatological point of view. Further research on species-specific reactions to the different UHI intensities is needed. Thus, for cooler or warmer areas, the optimal species can be selected. In cooler areas, these are trees that develop their leaves even at lower temperatures and provide cooling as early as possible. In warmer areas, the species must be particularly resistant to heat, so as not to prematurely throw off their leaves in hot summers. For this purpose, comprehensive studies over several years would be useful. Based on the measured developments, future scenarios could then be created using modeling. The number of studies on the influence of green infrastructure on the temperature has increased rapidly in recent years [31-33]. For such modeling, basic work such as the present one is important because it provides input parameters. As has been shown recently, tree characteristics are also influenced by climate change and the standardized parameters collected in the past are no longer up-to-date. Among other factors, rising temperatures and the associated extension of the growing season are cited as the cause of the increased wood growth and the simultaneously reduced wood density; as a result, the estimated amount of carbon stored by trees is lower than assumed [34]. In line with this, the question arises as to how climate change will affect urban trees and their ecosystem services in future, since the trees not only mitigate the UHI effect, for example by cooling the surface, but are also themselves influenced by the UHI. This influence will intensify in the future and more research and monitoring is needed to understand this relationship. In exploring the interrelations of microclimate and urban trees, future developments must also be considered. This is the best way to ensure that the urban population can fully and most efficiently benefit from the ecosystem services of urban trees in the long term.

Author Contributions: Conceptualization, C.H.S. and A.H.; Data curation, C.H.S.; Formal analysis, C.H.S.; Funding acquisition, A.H.; Investigation, C.H.S. and C.H.; Methodology, C.H.S. and A.H.; Project administration, A.H.; Supervision, A.H.; Validation, C.H.S.; Visualization, C.H.S.; Writing-original draft, C.H.S., C.H., and A.H.; Writing-review and editing, C.H.S., C.H. and A.H. 
Funding: This work was supported by the Sparkling Science research program of the Federal Ministry of Science, Research and Economy (BMWFW), Austria, project "Urban trees as climate messengers", grant number SPA 06/005. We are grateful for financial support provided by the Open Access Publication Fund of the University of Salzburg.

Acknowledgments: Open Access Funding by the University of Salzburg. We thank Christian Stadler, as well as Michael Heinl (Stadt:Gärten Salzburg), Günther Nowotny, Matthias Marbach, Laurenz Fiala, and Sten Gillner for administrative and technical support.

Conflicts of Interest: The authors declare no conflict of interest. The funders had no role in the design of the study; in the collection, analyses, or interpretation of data; in the writing of the manuscript; or in the decision to publish the results.

\section{References}

1. Nikodinoska, N.; Paletto, A.; Pastorella, F.; Granvik, M.; Franzese, P.P. Assessing, valuing and mapping ecosystem servides at city level: The case of Uppsala (Sweden). Ecol. Model. 2018, 368, 411-424. [CrossRef]

2. Leal Filho, W.; Echevarria Icaza, L.; Neht, A.; Klavins, M.; Morgan, E.A. Coping with the impacts of urban heat islands. A literature based study on understanding urban heat vulnerability and the need for resilience in cities in a global climate change context. J. Clean. Prod. 2018, 171, 1140-1149. [CrossRef]

3. Gill, S.E.; Handley, J.F.; Ennos, A.R.; Pauleit, S. Adapting cities for climate change: The role of the green infrastructure. Built Environ. 2007, 33, 115-133. [CrossRef]

4. Gago, E.J.; Roldan, J.; Pacheco-Torres, R.; Ordóñez, J. The city and urban heat islands: A review of strategies to mitigate adverse effects. Renew. Sustain. Energy Rev. 2013, 25, 749-758. [CrossRef]

5. Loughner, C.P.; Allen, D.J.; Zhang, D.-L.; Pickering, K.E.; Dickerson, R.R.; Landry, L. Roles of Urban Tree Canopy and Buildings in Urban Heat Island Effects: Parameterization and Preliminary Results. J. Appl. Meteorol. Climatol. 2012, 51, 1775-1793. [CrossRef]

6. Bowler, D.E.; Buyung-Ali, L.; Knight, T.M.; Pullin, A.S. Urban greening to cool towns and cities: A systematic review of the empirical evidence. Landsc. Urban Plan. 2010, 97, 147-155. [CrossRef]

7. Lin, B.-S.; Lin, Y.-J. Cooling Effects of Shade Trees with Different Characteristics in a Subtropical Urban Park. HortScience 2010, 45, 83-86. [CrossRef]

8. Rahman, M.A.; Moser, A.; Gold, A.; Rötzer, T.; Pauleit, S. Vertical air temperature gradients under the shade of two contrasting urban tree species during different types of summer days. Sci. Total Environ. 2018, 633, 100-111. [CrossRef]

9. Mao, L.-S.; Gao, Y.; Sun, W.-Q. Influences of street tree systems on summer micro-climate and noise attenuation in Nanjing City, China. Arboric. J. 1993, 17, 239-251. [CrossRef]

10. Gillner, S.; Vogt, J.; Tharang, A.; Dettmann, S.; Roloff, A. Role of street trees in mitigating effects of heat and drought at highly sealed urban sites. Landsc. Urban Plan. 2015, 143, 33-42. [CrossRef]

11. Roloff, A. Bäume in der Stadt; Ulmer Verlag: Stuttgart, Germany, 2013.

12. Chmielewski, F.-M.; Rötzer, T. Response of tree phenology to climate change across Europe. Agric. For. Meteorol. 2001, 108, 101-112. [CrossRef]

13. Holz, I.; Franzaring, J.; Böcker, R.; Fangmeier, A. Eintrittsdaten phänologischer Phasen und ihre Beziehung zu Witterung und Klima; LUBW: Karlsruhe, Germany, 2011.

14. Zipper, S.C.; Schatz, J.; Singh, A.; Kucharik, C.J.; Townsend, P.A.; Loheide II, S.P. Urban heat island impacts on plant phenology: Intra-urban variability and response to land cover. Environ. Res. Lett. 2016, 11, 1-12. [CrossRef]

15. Salzburg, Austria Köppen Classification: Marine West Coast Climate. Available online: https://www. weatherbase.com/weather/weather-summary.php3?s=5111\&cityname=Salzburg, +Austria (accessed on 12 June 2019).

16. Zentralanstalt für Meteorologie und Geodynamik (ZAMG) Klimadaten von Österreich 1971-2000. Available online: http://www.zamg.ac.at/fix/klima/oe71-00/klima2000/klimadaten_oesterreich_1971_fr (accessed on 12 June 2019).

17. Zentralanstalt für Meteorologie und Geodynamik (ZAMG) Stadtklima Zukunft. Available online: https: //www.zamg.ac.at/cms/de/klima/informationsportal-klimawandel/daten-download/stadtklima-zukunft (accessed on 12 June 2019). 
18. ESRI Inc. (Environmental Systems Research Institute) Datenklassifikationsmethoden. Available online: https://pro.arcgis.com/de/pro-app/help/mapping/layer-properties/data-classification-methods.htm (accessed on 12 June 2019).

19. Vogt, J.; Gillner, S.; Hofmann, M.; Tharang, A.; Dettmann, S.; Gerstenberg, T.; Schmidt, C.; Gebauer, H.; Van de Riet, K.; Berger, U.; et al. Citree: A database supporting tree selection for urban areas in temperate climate. Landsc. Urban Plan. 2017, 157, 14-25. [CrossRef]

20. Wesolowski, T.; Rowinski, P. Timing of bud burst and tree-leaf development in a multispecies temperate forest. For. Ecol. Manag. 2006, 237, 387-393. [CrossRef]

21. Batorczak, A. The Beagle Project. In Biodiversity in Education for Sustainable Development - Reflection on School-Research Cooperation; Ulbrich, K., Settele, J., Benedict, F.F., Eds.; Pensoft Publishers: Sofia, Bulgarien, 2010; pp. 53-55.

22. LI-COR, Inc. LAI-2200C Plant Canopy Analyzer Instruction Manual; LI-COR: Lincoln, NE, USA, 2013.

23. Plietzsch, A. Die Lebensdauer von Bäumen und Möglichkeiten zur Altersbestimmung. In Jahrbuch der Baumpflege 2009; Dujesiefken, D., Ed.; Haymarket Media Gmbh: Braunschweig, Germany, 2008; pp. 172-188.

24. Flynn, D.F.B.; Wolkovich, E.M. Temperature and photoperiod drive spring phenology across all species in a temperate forest community. New Phytol. 2018, 219, 1353-1362. [CrossRef] [PubMed]

25. Fu, Y.H.; Campioli, M.; Deckmyn, G.; Janssens, I.A. The Impact of Winter and Spring Temperatures on Temperate Tree Budburst Dates: Results from an Experimental Climate Manipulation. PLoS ONE 2012, 7, e47324. [CrossRef] [PubMed]

26. Endreny, T.A. Strategically growing the urban forest will improve our world. Nat. Commun. 2018, 9, 1160. [CrossRef] [PubMed]

27. Caffarra, A.; Donnelly, A. The ecological significance of phenology in four different tree species: Effects of light and temperature in bud burst. Int. J. Biometeorol. 2011, 55, 711-721. [CrossRef]

28. McPherson, E.G.; Berry, A.M.; van Doorn, N.S. Performance testing to identify climate-ready trees. Urban For. Urban Green 2018, 29, 28-39. [CrossRef]

29. Bréda, N.J.J. Ground-based measurements of leaf area index: A review of methods, instruments and current controversies. J. Exp. Bot. 2003, 54, 2403-2417. [CrossRef] [PubMed]

30. Gómez-Muñoz, V.M.; Porta-Gándara, M.A.; Fernández, J.L. Effect of tree shades in urban planning in hot-arid climatic regions. Landsc. Urban Plan. 2010, 94, 149-157. [CrossRef]

31. Ambrosini, D.; Galli, G.; Mancini, B.; Nardi, I.; Sfarra, S. Evaluating Mitigation Effects of Urban Heat Islands in a Historical Small Center with the ENVI-MetßClimate Model. Sustainability 2014, 6, 7013-7029. [CrossRef]

32. Zuvela-Aloise, M.; Koch, R.; Buchholz, S.; Früh, B. Modelling the potential of green and blue infrastructure to reduce urban heat load in the city of Vienna. Clim. Chang. 2016, 135, 425-438. [CrossRef]

33. Salata, F.; Golasi, I.; Petitti, D.; de Lieto Vollaro, E.; Coppi, M.; de Lieto Vollaro, A. Relating microclimate, human thermal comfort and health during heat waves: An analysis of heat island mitigation strategies through a case study in an urban outdoor environment. Sustain. Cities Soc. 2017, 30, 79-96. [CrossRef]

34. Pretzsch, H.; Biber, P.; Schütze, G.; Kemmerer, J.; Uhl, E. Wood density reduced while wood volume growth accelerated in Central European forests since 1870. For. Ecol. Manag. 2018, 429, 589-616. [CrossRef]

(C) 2019 by the authors. Licensee MDPI, Basel, Switzerland. This article is an open access article distributed under the terms and conditions of the Creative Commons Attribution (CC BY) license (http://creativecommons.org/licenses/by/4.0/). 